EDITORIAL:-

\title{
DIABETES AND HYPERTENSION: ISSUES OF TREATMENT COMPLIANCE.
}

Over the past few years the number of patient diagnosed with hypertension or diabetes mellitus gets on increasing. However majority of these people either do not start their treatment or continue as advised by their doctor. The reason why most people did not want to take medicines is because of their belief that once started they have to continue it until their death. Another group of patients who may not like to take medicines is because of their financial difficulties. How should we solve this problem to enhance their compliance to the treatment offered?

We would need a multidisciplinary approach where every medical personal, who encounter these patients, encourage them to take medicines by explaining the various possible complications of diabetes and Hypertension and also by educating them to control their BP and blood sugar. Some degree of fear created in the patients if they remain without medications would be an intrinsic force that would make them to start and remain adherent to medications.

Public awareness program should also be organized through media. Such programs should focus on motivating patients to seek health maintenance examination and also adopting healthy life style. We should also include pharmacist in this process because there are a group of patients who try to find out the reason why medicines have been instituted to them by physicians. They would also ask to find out the appropriateness of the treatment plan.

These are the very simple tasks that we recommend every physician to follow, so that any untoward events may not likely to happen in future. The basic principle is: once your patient complies with your treatment plan, he or she will definitely get benefit and thanks you. 